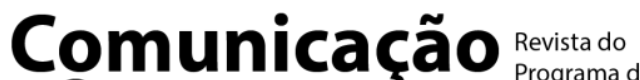

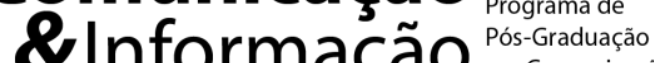 em Comunicação
}

\section{Potencialidades e Limites do Fact-Checking no Combate à Desinformação}

\author{
Potentials and Limits of Fact-Checking in the Fight Against Misinformation
}

\author{
Potencialidades y Limites del Fact-Checking en el Combate a la \\ Desinformación
}

\author{
Carlos Roberto Praxedes dos Santos ${ }^{l}$ \\ Camila Maurer $^{2}$
}

\begin{abstract}
Resumo
A disseminação de informações falsas nos mais diversos níveis impõe desafios ao jornalismo profissional. $\mathrm{O}$ presente artigo discute potencialidades e limites dessa prática no combate à desinformação a partir de uma análise crítica da metodologia de checagem adotada pela Agência Lupa. Para isso, toma-se como base pesquisa bibliográfica acerca da contextualização histórica do factchecking a partir de Graves (2016) e dos conceitos de verdade e objetividade propostos, respectivamente, por Tambosi (2007) e Sponholz (2009). Conclui-se que a prática apresenta potencialidades por corrigir informações enganosas e pela proposta de transparência em relação aos métodos utilizados, mas também encontra limites relacionados às dificuldades inerentes à complexidade da tarefa que se propõe a assumir.
\end{abstract}

Palavras-chave: Checagem de fatos. Verdade. Objetividade.

\begin{abstract}
The dissemination of false information at many levels poses challenges to professional journalism. This article discusses the potentials and limits of this practice in the fight against misinformation based on a critical analysis of the methodology used by Agência Lupa. For this, it is based on a bibliographical research about the historical contextualization of fact-checking from Graves (2016) and the concepts of truth and objectivity proposed, respectively, by Tambosi (2007) and Sponholz (2009). It is concluded that the practice presents potentials for correcting misleading information and for the proposal of transparency in relation to the methods used, but also finds limits related to the difficulties inherent in the complexity of the task it proposes to assume.
\end{abstract}

Keywords: Fact-checking. Truth. Objectivity.

\section{Resumen}

La diseminación de informaciones falsas en los más diversos niveles impone desafíos al periodismo profesional. El presente artículo discute potencialidades y límites de esa práctica en el combate a la desinformación a partir de un análisis crítico de la metodología de verificación adoptada por la Agencia Lupa. Para ello, se toma como base investigación bibliográfica acerca de la contextualización

1 Jornalista. Mestre em Gestão de Políticas Públicas (UNIVALI). Doutorando em Comunicação e Linguagens na Universidade Tuiuti do Paraná (UTP). Professor no Curso de Jornalismo da Universidade do Vale do Itajaí (UNIVALI), em Itajaí, Santa Catarina.

2 Jornalista. Aluna especial no Mestrado no Programa de Pós-Graduação em Jornalismo da Universidade Federal de Santa Catarina. 
histórica del fact-checking a partir de Graves (2016) y de los conceptos de verdad y objetividad propuestos, respectivamente, por Tambosi (2007) y Sponholz (2009). Se concluye que la práctica presenta potencialidades por corregir informaciones engañosas y por la propuesta de transparencia en relación con los métodos utilizados, pero también encuentra límites relacionados a las dificultades inherentes a la complejidad de la tarea que se propone asumir.

Palabras clave: Fact-checking. Verdade. Objetividade.

\section{INTRODUÇÃO}

Fake news foi eleita a palavra do ano de 2017 pelo dicionário britânico Collins, que a definiu como "informações falsas, muitas vezes sensacionalistas, divulgadas sob o disfarce de notícias" (FLOOD, 2017). A explosão no uso do termo lhe garantiu um verbete na edição impressa do dicionário em questão e presença cativa no discurso político contemporâneo. No entanto, considera-se que ele não seja capaz de designar com precisão o fenômeno da produção, disseminação e consumo de informações falsas, cujo espectro abrange desde sátiras e paródias até conteúdos fabricados com o objetivo de enganar e causar dano (WARDLE; DERAKHSHAN, 2017).

Esse contexto impõe desafios ao jornalismo profissional, que tem o fato como matériaprima e a busca da verdade como imperativo ético (BUCCI, 2000). Nesse cenário, iniciativas de checagem de fatos ganham notoriedade ao se apresentarem como alternativa para garantir ao público informação cuja veracidade tenha sido previamente checada. Embora iniciativas desse tipo existam desde os anos 1990, elas têm crescido em quantidade e abrangência no Brasil e no exterior nos últimos anos. Atualmente, existem mais de 160 iniciativas de factchecking ativas no mundo ${ }^{3}$. No Brasil, nove plataformas se dedicam à prática, entre veículos da grande imprensa e iniciativas independentes. Quatro delas (Agência Lupa, Aos Fatos, Truco e Estadão Verifica) são certificadas pela International Fact-Checking Network (IFCN), por seguirem premissas consideradas básicas pela entidade, tais como ser transparente em relação às fontes, financiamento e metodologia de trabalho, além de agir de forma apartidária e dispor de uma política de correção de erros ${ }^{4}$.

Partindo do pressuposto de que informação falsa não gera conhecimento (TAMBOSI, 2007) e considerando que a disseminação de informações falsas travestidas de notícia afeta a percepção do público em relação à credibilidade jornalística, podemos inferir que o fenômeno da desinformação constitui obstáculo para o jornalismo enquanto forma social de produção de

\footnotetext{
Duke Reporters' Lab, disponível em https://reporterslab.org/fact-checking/, acesso em 03 Fev. 2019.

Disponível em: https://ifcncodeofprinciples.poynter.org/know-more/the-commitments-of-the-code-ofprinciples, acesso em 23 Jan. 2018.
} 
conhecimento. Desse modo, julga-se importante lançar um olhar crítico sobre as iniciativas de fact-checking, tendo em vista que elas se apresentam ao público como ferramentas para combater o fenômeno, atuando principalmente em duas frentes: checagem de declarações de figuras públicas e desmistificação de boatos e conteúdo fraudulento.

Nesse contexto, a proposta é discutir potencialidades e limites do fact-checking enquanto recurso no combate à desinformação. Para isso, pretende-se descrever a proposta de atuação, os objetos e métodos da Agência Lupa, uma das primeiras iniciativas a trabalhar exclusivamente com checagem de fatos no Brasil. Objetiva-se, ainda, analisar criticamente a metodologia de seleção e checagem adotada pela plataforma na verificação de declarações publicadas pela imprensa e de boatos que circulam através das redes sociais. Para isso, tomase como base a metodologia descrita pela Agência Lupa em seu site, além de pesquisa bibliográfica sobre os conceitos de verdade e objetividade aplicados ao jornalismo.

\section{A BUSCA PELA VERDADE COMO OBJETIVO PRIMORDIAL}

Kovach e Rosenstiel (2004) definiram a verdade como a primeira obrigação do jornalismo, ao listarem os elementos básicos da profissão após pesquisa que envolveu centenas de profissionais nos Estados Unidos. A questão é unanimidade entre jornalistas, embora uma definição para o termo "verdade" esteja longe de ser ponto pacífico. Bucci (2000) ressalta que a busca da verdade dos fatos é o objetivo de toda a técnica jornalística e seu imperativo ético. O autor define o jornalismo como uma "ética baseada no combate à mentira ou, noutra perspectiva, na busca da verdade dos fatos - não na verdade metafísica, nem na verdade religiosa, muito menos na verdade científica, mas simplesmente da verdade dos fatos" (BUCCI, 2000, p. 51).

Tambosi (2007) discorda da redução do conceito ao imperativo ético presente nos códigos deontológicos, sem considerar a questão epistemológica e sua relação com as teorias provenientes da filosofia e das ciências. $\mathrm{O}$ autor alerta para a inexistência de uma teoria geral e completa da verdade, tendo em vista que se trata de um conceito filosófico complexo e controverso. Considerando as três teorias da verdade predominantes no contexto da teoria do conhecimento (a da correspondência, da coerência e da utilidade), o autor conclui que a teoria da verdade como correspondência é a que mais se adequa ao jornalismo, tendo em vista que este se situa no plano linguagem-mundo, discurso-realidade e deve, necessariamente, reportar os fatos. Esta teoria baseia-se no pressuposto de que "a verdade de uma proposição consiste em sua relação com o mundo, isto é, uma correspondência com os fatos ou estados de coisas" (TAMBOSI, 2007, p. 37). 
Aliada à concepção epistemológica de verdade como correspondência encontra-se o conceito de objetividade como adequação de uma representação à realidade (SPONHOLZ, 2009). No caso da objetividade jornalística, um "sistema de regras que tem como objetivo a produção de uma semelhança estrutural entre a realidade social e a realidade midiática" (SPONHOLZ, 2009, p. 17). A busca por tal semelhança tem como base a concepção de que é possível afirmar se as informações presentes em uma declaração descritiva são condizentes ou não com a realidade através da verificação.

Kovach e Rosenstiel (2004, p. 113) afirmaram que "a essência do jornalismo é a disciplina da verificação", defendendo ser este o principal diferencial do jornalismo em relação ao entretenimento, à propaganda, à literatura e à arte.

\begin{abstract}
No esclarecimento desses mal-entendidos e na melhora da disciplina da verificação reside o passo mais importante que os jornalistas podem dar para a qualidade da informação e a discussão pública. No fim, essa disciplina é o que separa o jornalismo de outros campos e cria uma razão econômica para sua sobrevivência. Uma disciplina mais consciente da verificação é o melhor antídoto para evitar que o velho jornalismo de verificação seja atropelado pelo jornalismo de afirmação, e forneceria aos cidadãos uma base para confiar nos relatos jornalísticos (KOVACH; ROSENSTIEL, 2004, p. 122).
\end{abstract}

Tambosi (2007, p. 45) aponta a excessiva dependência das fontes como um problema para o jornalismo na busca pela verdade ao afirmar que "o jornalista está exposto diariamente a afirmações cuja veracidade sequer pode investigar, notadamente na cobertura política. Em decorrência, facilmente se pode confundir afirmações (das fontes) com fatos". O autor vai mais longe, ao defender que "quanto mais declaratório for o jornalismo, quanto mais depender exclusivamente de fontes, mais difícil será sustentar que seja uma forma de conhecimento autônoma" (TAMBOSI, 2005, p. 37).

Nobre-Correia (2018) também cita o jornalismo de declarações ao descrever a relação da mídia com o que ele chama de "pseudoacontecimento dos poderes". O autor sustenta que os governantes utilizam a imprensa para conquistar notoriedade, produzindo acontecimentos que só existem em função da mídia, como declarações, conferências de imprensa, entrevistas exclusivas e participações em manifestações públicas. Para o autor,

[...] cai-se assim regularmente num jornalismo de declarações. Declarações que são muitas vezes difíceis de eliminar, mesmo quando não trazem nada ou pouca coisa de novo. Declarações que enchem, no entanto, as páginas ou o tempo de antena dos jornais em detrimento de informações provenientes de um trabalho de investigação da redação (NOBRE-CORREIA, 2018, p. 186). 
O uso indiscriminado desse tipo de recurso no jornalismo profissional expõe uma fragilidade do trabalho da imprensa, que leva ao conhecimento do público declarações cuja veracidade não fora previamente verificada, utilizando o recurso das aspas como escudo e adotando uma concepção errônea de objetividade enquanto neutralidade. Nesse contexto, lembra-se o alerta de Sponholz (2009, p. 29):

\footnotetext{
Neutralidade pode prejudicar o processo de conhecimento não somente por causa da renúncia à investigação jornalística, mas também porque a redução à mera tarefa de divulgação pode levar à transmissão de declarações falsas. Como o jornalista não pesquisa, as declarações também não são verificadas (por exemplo, confrontadas com as de uma segunda fonte). Dessa forma, o jornalista se torna manipulável.
}

Sob esse prisma, considera-se necessária e louvável a iniciativa de verificar se as informações contidas nas declarações das fontes condizem ou não com a realidade. $\mathrm{O}$ fato de essa verificação raramente acontecer durante o processo de produção da notícia demonstra desinteresse do jornalismo na busca pela verdade dos fatos e abre espaço para a atuação de agências especializadas em fact-checking, que enxergam essa brecha dos veículos tradicionais como uma oportunidade de mercado.

\section{FENÔMENO DA DESINFORMAÇÃO}

A popularização das iniciativas de checagem está inserida em um contexto de disseminação de informações falsas nos mais diversos níveis. O termo fake news adquiriu popularidade no contexto das eleições de Donald Trump para a presidência dos Estados Unidos e da saída do Reino Unido da União Europeia. A influência das informações falsas sobre os processos eleitorais é algo ainda impossível de mensurar, mas constitui preocupação em escala global. No contexto brasileiro, o problema adquire contornos ainda mais críticos tendo em vista que uma parcela importante do consumo de informação se dá através de aplicativos de troca de mensagens instantâneas, como o WhatsApp, que tem 120 milhões de usuários no Brasil (WHATSAPP, 2017) o que faz com que a discussão política migre para ambientes privados, nos quais não há controle do conteúdo, cabendo apenas ao usuário a tarefa de identificar se uma informação é verdadeira ou falsa. Desse modo, a desinformação encontra no WhatsApp terreno fértil para se multiplicar de forma praticamente impossível de rastrear, contexto que traz à tona a necessidade de incluir a reflexão sobre educação midiática nas discussões acerca do combate à desinformação.

O uso do termo fake news tem sido banalizado pelo discurso político, sendo frequentemente utilizado como estratégia narrativa para desacreditar e restringir o trabalho da 
imprensa. Nesse contexto, acredita-se que o uso exagerado dessa terminologia possa ter efeito danoso sobre a percepção do público em relação à credibilidade jornalística, ao associar a notícia, uma especificidade do trabalho jornalístico, ao adjetivo "falso". Para Wardle e Derakhshan (2017), o termo é inadequado para descrever o complexo fenômeno da produção, disseminação e consumo de informações falsas. Os autores propõem uma definição baseada no nível de falsidade e dano do conteúdo, identificando três tipos de informação que fazem parte do panorama do que eles chamam de desordem da informação: misinformation (informação incorreta, em tradução livre), que define o compartilhamento de informação falsa, mas sem a intenção explícita de causar dano; disinformation (desinformação, em tradução livre), quando a informação é compartilhada com a intenção de causar dano; e malinformation (mal-informação, em tradução livre), que constitui informação verdadeira, compartilhada com o objetivo de causar dano, como no caso de vazamentos de conteúdo privado ou íntimo.

Considerando as categorias propostas por Wardle e Derakhshan (2017), pode-se dizer que o alvo da atuação das agências de checagem corresponde ao que os autores chamam de misinformation (informação incorreta), nos casos em que os jornalistas verificam a exatidão dos dados citados por figuras públicas em declarações à imprensa (levando em consideração que não é possível dizer se há intenção de causar dano), e disinformation (desinformação), quando desmentem boatos fabricados e disseminados nas redes sociais.

\section{ADVENTO DO FACT-CHECKING POLÍTICO}

Graves (2016), define o fact-checking como um "movimento de reforma", que busca resgatar princípios que balizaram o jornalismo moderno, como verdade e objetividade. Seu advento remonta à eleição de Ronald Reagan em 1980, que chegou à presidência dos Estados Unidos no ano seguinte carregando a reputação de cometer erros e exageros frequentes em suas afirmações, o que levou alguns veículos a checar suas declarações em conferências de imprensa e pronunciamentos na TV. O jornal The Washington Post chegou a publicar reportagens sobre as conferências de imprensa do então presidente acompanhadas de barras laterais com informações adicionais que destacavam e corrigiam declarações que continham erros. A iniciativa foi utilizada com frequência durantes os dois primeiros anos de mandato, mas posteriormente descontinuada, após reclamações dos leitores (DOBBS, 2012).

As eleições presidenciais de 1988, nos Estados Unidos, foram marcadas pelo uso de informações falsas nas propagandas eleitorais de ambos os candidatos, George H. W. Bush e 
Michael Dukakis. Nesse contexto, surgiram as primeiras iniciativas do gênero Ad Watch ${ }^{5}$ que se multiplicaram durante as eleições legislativas de 1990 nas emissoras de televisão e jornais e já estavam presentes em 80\% dos maiores jornais dos Estados Unidos em 2006 (GRAVES, 2016). Brooks Jackson, correspondente de política da CNN, foi um dos jornalistas a adotar o formato a partir de 1991, passando a checar declarações, além das propagandas, adotando para isso o termo "fact-check". Em 2003, Jackson lançou seu próprio site, FactCheck.org, com recursos provenientes da Annemberg Foundation. A partir de então, novas iniciativas de fact-checking começaram a se proliferar em jornais e emissoras de TV dos Estados Unidos, estando hoje presentes em todos os principais veículos de imprensa do país.

No Brasil, as primeiras iniciativas pontuais de checagem de fatos foram registradas durante as campanhas eleitorais de 2010 e 2014. Muitas, no entanto, foram descontinuadas após esse período. O blog Preto no Branco ${ }^{6}$, do jornal O Globo, é considerado o primeiro projeto brasileiro de fact-checking, lançado em 2014 com foco nas eleições presidenciais. Descontinuado no ano seguinte, sua criadora, a jornalista Cristina Tardáguila, fundou a Agência Lupa, uma das pioneiras plataformas a se dedicar exclusivamente ao fact-checking.

\subsection{AGÊNCIA LUPA}

Apresenta-se ao público como ferramenta para desmentir discursos políticos mentirosos. Produz checagens em formato de texto, áudio e vídeo que são vendidas a veículos tradicionais de imprensa e publicadas no site da agência. Tem a Editora Alvinegra, responsável pela publicação da revista piauí, como principal investidor, além de hospedar seu conteúdo no site da mesma revista (Grupo Folha/Uol). Além da verificação de declarações políticas oficiais, a partir de 2018 começou a trabalhar também com o chamado debunking, desmentindo boatos que circulam através das redes sociais.

A agência afirma seguir uma metodologia inspirada nos processos utilizados por outras plataformas do gênero, como o Politifact ${ }^{7}$, nos Estados Unidos, e o Chequeado ${ }^{8}$, na Argentina. De acordo com material institucional acerca de seu método, o processo tem início com a observação diária do que é dito por políticos, líderes sociais e celebridades nos veículos de comunicação. A partir dessa observação, são selecionadas as frases que serão checadas,

\footnotetext{
5 O termo Ad Watch é utilizado por Graves (2016) para se referir à checagem do conteúdo de propaganda política.

6 Disponível em: https://blogs.oglobo.globo.com/preto-no-branco/

7 Plataforma de fact-checking com sede nos Estados Unidos fundado pelo jornalista estadunidense Bill Adair em 2007, vencedora do Prêmio Pulitzer em 2009. Disponível em: https://www.politifact.com/

8 Plataforma de fact-checking com sede na Argentina, atuante desde 2010. Primeiro projeto de checagem de fatos da América Latina. Disponível em: https://chequeado.com/
} 
considerando três critérios de relevância: dão preferência a declarações de personalidades de destaque nacional, assuntos de interesse público que afetem o maior número de pessoas possível e/ou que tenham sido destaque na imprensa ou na internet recentemente. Selecionada a frase, passa-se a fazer um levantamento de "tudo" o que foi publicado sobre o assunto em jornais, revistas e sites. A partir de então, o jornalista inicia a busca por informações públicas em bases de dados oficiais. Quando os dados encontrados são insuficientes ou inexistentes, o jornalista pode fazer um pedido de informações via Lei de Acesso à Informação ou às assessorias de imprensa. Se julgar necessário, também pode ir à campo colher informações. Para concluir, ainda pode recorrer a especialistas para fornecer auxílio à compreensão dos dados. A etapa final da metodologia é solicitar a posição oficial da personalidade que foi checada. De acordo com a plataforma, o objetivo das checagens é verificar o grau de veracidade das frases que contenham dados históricos, estatísticos, comparações e informações relativas à legalidade ou constitucionalidade de um fato. A agência afirma que, com isso, pretende ser "um lugar ao que os brasileiros podem recorrer quando precisam tomar decisões - das mais simples às mais importantes" (LUPA, 2015). Depois de passarem pelo processo de checagem, as informações recebem uma das nove etiquetas utilizadas pela agência para classificar o material: "verdadeiro"; "verdadeiro, mas"; "ainda é cedo pra dizer"; "exagerado"; "contraditório"; "subestimado"; "insustentável”; "falso" e "de olho".

\subsubsection{Reflexões sobre a metodologia da Agência Lupa}

Não há pesquisas que revelem de forma conclusiva se as iniciativas de fact-checking e debunking são efetivas no combate à desinformação, de modo que não se pode afirmar que as plataformas estejam verdadeiramente qualificando o debate público. De todo modo, potencialidades e limites podem ser identificados, a partir de uma análise crítica da metodologia adotada pela Agência Lupa.

A principal e mais evidente potencialidade do trabalho desse tipo de plataforma é apontar erros no discurso de figuras públicas e corrigi-los, convertendo-se em um arquivo que pode ser consultado pelo cidadão em busca de informação de qualidade. Como movimento que se pretende "reformista", tem potencial para levar o jornalismo tradicional a repensar o atual modelo de produção da notícia baseado em ouvir e citar "os dois lados", colocando o jornalista no centro do processo de busca pela verdade.

Considerando que a transparência em relação aos métodos e processos constitui elemento fundamental para a criação de uma melhor disciplina da verificação (KOVACH; ROSENSTIEL, 2004), pode-se dizer que uma das maiores contribuições das agências 
especializadas em fact-checking é a transparência em relação aos métodos que utilizam. Ao trazer para a superfície do texto os procedimentos adotados para chegar às informações ali apresentadas, essas plataformas contribuem para educar o consumidor de informação em relação ao método jornalístico, que pode ser replicado pelo leitor na avaliação de outros conteúdos, contribuindo de forma efetiva para o combate à informação incorreta ou fraudulenta. Além disso, ajuda o público a compreender o que faz o jornalista e o que diferencia o texto jornalístico do conteúdo falso que circula via redes sociais.

O primeiro passo descrito na metodologia da plataforma em questão - observação diária do que é dito por políticos, líderes sociais e celebridades nos veículos de comunicação deixa dúvidas sobre a maneira como esse monitoramento é realizado, sobretudo se a observação é guiada pelo monitoramento das fontes mapeadas pela agência como relevantes ou pela pauta dos veículos de comunicação. Isto é, se há uma busca ativa por declarações de determinadas fontes, ou se a matéria-prima para o trabalho da agência é inteiramente pautada pelo que já foi noticiado por outros veículos e apenas a partir deste conteúdo já noticiado são aplicados os critérios de relevância citados na metodologia. Ainda sobre este quesito, poderia ser útil saber sobre as técnicas de monitoramento ou sobre o uso de alguma tecnologia específica para monitoramento de redes sociais, por exemplo, tendo em vista que é no ambiente digital que a desinformação se dissemina mais livremente.

A partir dessa observação, seleciona-se a frase a ser checada. Sobre esse aspecto, convém lembrar que uma frase pode ser verdadeira e, ainda assim, distorcer os fatos, dependendo do contexto adicionado a ela. Desse modo, julga-se importante destacar que o sucesso do processo de checagem que tem uma frase isolada como matéria-prima depende diretamente da capacidade de interpretação e análise dos jornalistas que conduzem esse processo.

Um dos critérios de relevância utilizados pela plataforma para selecionar as declarações a serem checadas é o destaque obtido pelo conteúdo na imprensa ou na internet. Sobre esse ponto, recorda-se o destacado por Wardle e Derakhshan (2017) sobre o uso da tecnologia para decidir quais conteúdos falsos devem ser desmentidos e quais devem ser ignorados, com base em algoritmos que permitem prever se eles apresentam potencial para atrair interação dos usuários da internet e se tornar virais.

Se certas histórias, rumores ou conteúdo visual, embora problemáticos, não estiverem ganhando força, toma-se a decisão de não fornecer oxigênio adicional a essa informação. A mídia precisa considerar que a publicação de desmistificações pode causar mais danos do que benefícios, especialmente porque os agentes por trás das campanhas de desinformação veem a amplificação da mídia como uma das 
principais técnicas para o sucesso. Debunks em si podem ser considerados uma forma de engajamento. A indústria de notícias precisa se unir para pensar sobre as implicações deste tipo de reportagem e os aspectos filosóficos e práticos da incorporação dessas ideias relacionadas ao silêncio estratégico (WARDLE; DERAKHSHAN, 2017, p. 19, tradução nossa).

Desse modo, considera-se salutar a preocupação da plataforma em trazer à tona assuntos que estejam ganhando destaque. A metodologia da Agência Lupa não informa se alguma tecnologia específica é utilizada para fornecer subsídios às decisões editoriais e evitar que boatos com pouco engajamento ganhem amplitude através da plataforma.

Após a seleção do conteúdo a ser checado, o jornalista faz um levantamento de "tudo" o que foi publicado sobre o assunto em jornais, revistas e sites. Chama atenção o fato de a própria agência colocar o termo "tudo" entre aspas no material institucional em que descreve sua metodologia, evidenciando que esse levantamento integral é inviável no contexto de abundância de informação propiciado pelo ambiente digital. Considerando ser este o primeiro passo da checagem propriamente dita, há que se considerar o fato de que o processo tem início a partir da coleta de informação já publicada, ou seja, já processada de acordo com filtros editoriais de terceiros. Pode-se questionar se esse procedimento influencia de alguma forma o resultado final da checagem.

$\mathrm{Na}$ fase seguinte, os jornalistas da agência buscam informações públicas em bases de dados oficiais ou via Lei de Acesso à Informação para afirmar se uma determinada declaração corresponde à realidade dos fatos. Ao fazerem isso, revitalizam a busca da verdade enquanto correspondência aos fatos e trabalham sob uma perspectiva epistemológica de objetividade, ao buscar uma semelhança estrutural entre a realidade social e a realidade midiática. No entanto, a dependência excessiva de dados e informações oficiais pode constituir uma fragilidade do método em determinadas situações, tendo em vista que o acesso a esse conteúdo pode ser deliberadamente obstruído ou dificultado por razões diversas. Exemplo disso é a recente tentativa de alteração, via decreto federal, da quantidade de servidores com autorização para decretar sigilo ultrassecreto em documentos do governo ${ }^{9}$.

A metodologia descreve, ainda, que o jornalista pode ir a campo "se julgar necessário", o que evidencia que o trabalho é majoritariamente realizado no interior da redação. Acredita-se que reportagem em campo poderia ajudar a tornar o material mais profundo, expondo melhor as nuances e controvérsias que, por vezes, envolvem a questão checada. Uma situação citada pela ombudsman contratada para atuar na Agência Lupa durante

9 O Decreto n. 9.690 de 23 de janeiro de 2019, disponível em: http://www.planalto.gov.br/ccivil 03/_ato20192022/2019/decreto/D9690.htm foi barrado pelo Congresso Federal em 19 de fevereiro de 2019, com 367

votos a favor da suspensão do decreto, 57 contrários e 3 abstenções. 
o período eleitoral de 2018, Fernanda da Escóssia, exemplifica de forma simples essa situação: ao checar uma declaração do então candidato à presidência Fernando Haddad, a plataforma afirmou que o preço médio do botijão de gás de cozinha no país em setembro de 2018 era R\$ 68,48, classificando como “exagerada" a declaração do candidato, ao dizer que o produto custava $\mathrm{R} \$ 80,00^{10}$. A checagem foi feita com base em dados oficiais da Agência Nacional de Petróleo, Gás Natural e Biocombustíveis. Após a publicação, no entanto, leitores afirmaram que, na prática, o produto custa mais. Nas palavras da ombudsman: "a Lupa deveria, de planilha na mão, percorrer os pontos de venda. Tenho insistido na necessidade de que a verificação seja feita também na rua, abraçando a boa e velha reportagem. A metodologia permite, os leitores ganham" (ESCOSSIA, 2018).

Compreende-se que o uso de etiquetas para classificar o conteúdo checado de acordo com seu nível de veracidade seja pensado para o consumo de informação no ambiente digital e sirva como chamariz para a leitura da reportagem completa. No entanto, seu uso é questionável, pois, por mais objetivos que sejam os fatos considerados durante o processo de verificação, eles fazem parte de um contexto que pode ser - e frequentemente é - amplo e complexo, de modo que atribuir uma etiqueta é sempre uma decisão editorial e não o resultado de uma operação matemática. Nesse contexto, é válido citar que uma pesquisa de doutorado realizada no departamento de Ciência Política da Universidade de Stanford, nos Estados Unidos, revelou que raramente as plataformas de checagem ${ }^{11}$ se dedicam a verificar o mesmo assunto ou declaração e, quando as checagens coincidem, as conclusões frequentemente são diferentes. Uma declaração classificada como "majoritariamente verdadeira" por uma plataforma chegou a ser classificada como "falsa" por outra, o que exemplifica a complexidade desse tipo de decisão (LIM, 2018).

A própria plataforma deixa claro que existe um limite para o que pode ser checado a partir de sua metodologia, ao afirmar que:

\footnotetext{
A Lupa não checa opiniões (a não ser quando elas sejam contraditórias - nesse caso levam essa etiqueta). A Lupa não faz previsões de futuro. Não aponta tendências nem avalia conceitos amplos. Esforça-se para verificar o grau de veracidade de frases que contenham dados históricos, estatísticos, comparações e informações relativas à legalidade ou constitucionalidade de um fato (LUPA, 2015).
}

Desse modo, impõe-se um limite bastante restrito para o que pode se tornar objeto de checagem, deixando de fora muitos aspectos necessários para que se possa construir uma

10 Disponível em: https://piaui.folha.uol.com.br/lupa/2018/10/25/fim-campanha-bolsonaro-haddad/

11 Foram objetos da pesquisa as plataformas Politifact e Fact Checker (LIM, 2018). 
compreensão da realidade social. Sobre esse aspecto, recorda-se a crítica do cientista político Luis Felipe Miguel em relação às plataformas de fact-checking, ao dizer que "há um poderoso reforço à ideia de que a 'realidade' é uma coleção de fatos 'objetivos', independentes da narrativa que os organiza, e portanto que o jornalismo 'imparcial' apresenta a seus leitores nada menos que a verdade" (MIGUEL, 2018). Nesse contexto, acredita-se que o poder de arbitragem da verdade conferido a essas plataformas deva ser relativizado.

\section{CONSIDERAÇÕES FINAIS}

O presente artigo buscou discutir potencialidades e limites do fact-checking no combate à desinformação. A análise da metodologia adotada pela Agência Lupa permitiu identificar que a prática traz contribuições ao atual contexto por lançar luz sobre declarações e textos incorretos ou mentirosos, trazendo à tona informações que correspondem à realidade dos fatos. Desse modo, acaba por iluminar, também, a fragilidade do jornalismo contemporâneo, que, sob o refúgio das aspas, erra ao tornar-se mero divulgador de declarações. Nesse contexto, considera-se necessário e urgente compreender os possíveis efeitos do fact-checking sobre a percepção do público em relação à credibilidade jornalística, tendo em vista que, para os consumidores do fact-checking, fica evidente que as declarações das fontes ouvidas pelos jornalistas dos veículos tradicionais podem conter informações enganosas.

Pode-se inferir, ainda, que a transparência dos métodos tem potencial para trazer maiores contribuições ao público do que a própria classificação das informações de acordo com escalas que podem suscitar (e frequentemente suscitam) uma diversidade de questionamentos e discordâncias. Nesse contexto, é válido lembrar que a Agência Lupa utiliza nove etiquetas para classificar o material verificado, o que evidencia o fato de que, entre o verdadeiro e o falso, há muitas nuances possíveis, nem sempre fáceis de identificar.

Nesse contexto, propõe-se, também, uma reflexão sobre o fato de a Agência Lupa assim como outras plataformas de checagem no Brasil e no exterior - atuar tanto na checagem da veracidade de declarações publicadas pela imprensa como no debunking de boatos e conteúdo falso fabricado com o objetivo de causar dano. Admite-se que ambas as atividades são importantes para a qualificação do debate público, mas há que se considerar que os dois tipos de informação apresentam naturezas diversas, o que nos leva a questionar se a união das duas atividades (fact-checking e debunking) na mesma plataforma possa contribuir para borrar ainda mais as linhas entre notícia e conteúdo falso travestido de notícia, aprofundando a crise de credibilidade dos veículos jornalísticos. 
Por fim, conclui-se que o fact-checking transformou o ponto de partida do processo de produção da notícia em produto final. Se pensarmos na prática como um movimento de reforma que busca resgatar princípios como verdade e objetividade, conforme descrito por Graves (2016), podemos inferir que seu ciclo de vida estará completo quando a verificação do que é dito pelas fontes de informação tornar-se rotina antes da publicação, e não depois dela, deixando para as plataformas de checagem a já suficientemente difícil missão de desmentir boatos e conteúdo fraudulento.

\section{REFERÊNCIAS}

BUCCI, Eugenio. Sobre ética e imprensa. São Paulo: Companhia das Letras, 2000.

DOBBS, Michael. The rise of political fact checking. Washinton, DC: News America Foundation, 2012.

ESCÓSSIA, Fernanda da. O urgente, o útil e o inútil na checagem jornalística. Folha de S. Paulo, 11 out. 2018. Disponível em: https://piaui.folha.uol.com.br/lupa/2018/10/11/colunaombudsman-urgente-util// Acesso em: 31 jan. 2018.

FLOOD, Alison. Fake news is 'very real'word of the year for 2017. The Guardian, 02 nov. 2017. Disponível em: https://www.theguardian.com/books/2017/nov/02/fake-news-is-veryreal-word-of-the-year-for-2017. Acesso em: 04 dez. 2018.

GRAVES, Lucas. Deciding what's true: the rise of political fact-checking in American journalism. New York: Columbia University Press, 2016.

KOVACH, Bill; ROSENSTIEL, Tom. Os elementos do jornalismo: o que os jornalistas devem saber e o público exigir. 2.ed. São Paulo: Geração Editorial, 2004.

LIM, CHLOE. Checking how fact-checkers check. Research \& Politics, v. 5, n. 3, Jul. 2018. Disponível em: https://doi.org/10.1177/2053168018786848. Acesso em: Acesso em: 04 dez. 2018.

LUPA a primeira agência de fact-checking do Brasil. Folha de S. Paulo, 15 out. 2015. Disponível em: https://piaui.folha.uol.com.br/lupa/2015/10/15/como-fazemos-nossaschecagens/. Acesso em 31 out. 2018.

MIGUEL, Luis Felipe. Checando o fact checking da Folha. Portal GGN, 08 abr. 2018. Disponível em: https://jornalggn.com.br/midia/checando-o-fact-checking-da-folha-por-luisfelipe-miguel/ Acesso em: 28 jan. 2019.

NOBRE-CORREIA, J.M. Teoria da informação jornalística. Coimbra: Almedina, 2018.

SPONHOLZ, Liriam. Jornalismo, conhecimento e objetividade: além do espelho e das construções. Florianópolis: Insular, 2009. 
TAMBOSI, Orlando. Informação e conhecimento no jornalismo. Estudos em Jornalismo e Mídia, v. 2, n. 2, 2005. Disponível em:

https://periodicos.ufsc.br/index.php/jornalismo/article/view/2139. Acesso em 22 Jan. 2019.

TAMBOSI, Orlando. Jornalismo e teorias da verdade. Intercom - Revista Brasileira de Comunicação, v. 30, n. 1, 2007. Disponível em: http://dx.doi.org/10.1590/rbcc.v30i1.279 Acesso em 02 dez. 2018.

WARDLE, Claire; DERAKHSHAN, Hossein. Information Disorder: toward an interdisciplinary framework for research and policy making. [S. l]: Council of Europe, 2017. Disponível em: https://rm.coe.int/information-disorder-toward-an-interdisciplinaryframework-for-researc/168076277c. Acesso em: 04 Dez. 2018

WHATSAPP chega a 120 milhões de usuários no Brasil. Estadão, São Paulo, 29 maio 2017. Disponível em: https://link.estadao.com.br/noticias/empresas,app-chega-a-120-milhoes-deusuarios-no-brasil,70001817647. Acesso em 08 out. 2019 